\title{
A Discourse on Ethnography
}

\author{
L. Harvey \\ School of Information Systems \\ Curtin Business School \\ Curtin University of Technology \\ Perth, Western Australia 6001, Australia \\ Tel: 093517685 \\ Fax: 093517685 \\ E-mail: harveyl@cbs.curtin.edu.au
}

\begin{abstract}
Ethnography is an approach to social inquiry developed by anthropologists and recently adopted by interpretive information systems researchers. In recent debates in anthropology, radical changes regarding appropriate approaches to ethnography have been presented. This paper looks at those changes and applies the debate to interpretive information systems research. The key assumption in this paper is that information systems is a discipline that is changing within a socio-historical context. Looking at interpretive information systems research as an emergent area in the discipline of information systems, an analysis is conducted of a product of the socio-historical context in order to illustrate the flux of changes which appear to be happening. These changes are related to the debates on ethnography in anthropology. The product of socio-historical disciplinary change which is analyzed is an unpublished Ph.D. thesis completed in the United States in 1988 (Orlikowski, 1988). The analysis is carried out through a textual re-reading of this thesis, concentrating on genres as indicators of flux in ideological changes regarding the move from an essentially realist genre to what may be described as a more evocative, or postmodern, genre. The importance of discourse and genre textuality is discussed. The aim in this paper is demonstrate how information systems researchers act within socio-historical contexts which reflect disciplinary changes. The argument is that information systems researchers can benefit
\end{abstract}


from reflecting upon their work in context and that the reflection provides a critical approach which complements the evaluation of research quality from philosophical principles. The view that the information systems research discipline is a historically-dependent social construction with evolving methodological principles is supported.

\section{INTRODUCTION}

Interpretive information systems research is emerging as an acceptable body of inquiry within the information systems discipline (Walsham 1995). Walsham argues that there are a number of approaches to interpretive research emerging, including that of ethnography (Orlikowski 1991a; Davies and Nielsen 1992; Myers 1994). In the interpretive research area, the information systems discipline has adopted ethnography from anthropology, seemingly by adopting ethnographic approaches used in the study of organisations (Orlikowski 1991a). Ethnography has the potential for contributing to the exploration of information systems research issues (Zuboff 1988; Orlikowski 1991a, 1992a; Lee 1993; Harvey and Myers 1995; Avison and Myers 1995) and has been discussed at workshop presentations in regard to this potential (Orlikowski 1991b; Lee 1992; Davies 1993).

The growing interest in ethnography indicates that it is worthwhile to investigate the adaptation of ethnography into information systems research. This requires a recognition that ethnography is a changing methodology both within source disciplines and, through adaptation, within the discipline of information systems. In this paper, the changes are presented and discussed but not in order to investigate ethnography as a set of rational principles. Instead, the investigation takes a historical and contextual perspective, looking at ethnography's emergence at one point in history. The purpose of doing so is to demonstrate that the adaptation of ethnography shows ambiguity and inconsistency in its assumptions as seen in the montage of genres expressed in an ethnographic text. The argument is that the ambiguity and inconsistency are not a sign of a poor quality ethnographic text but, rather, that they are an indicator of the struggle of expression which comes from writing an ethnography during a time of adaptation and change. The indication is that all research writings, including ethnographic texts, are dependent upon the socio-historical contexts of information systems knowledge development. Arguably, it seems important to recognize this dependency both when writing an ethnography and when reviewing ethnographic texts.

The genre adopted in this paper is that of a critical commentator, deconstructing an information systems ethnographic text. It is recognized that any deconstruction is itself a rewriting of a text. In this manner, the author is declaring an invitation to the reader to take part in a textual discourse, seeking to involve the reader in the debate while considering both the text under deconstruction and, eventually, the text of this paper. This is an essentially textual perspective seeing the reader as text interpreter, 
the author(s) as text constructor(s), and the analytical investigator as text deconstructor (Derrida, translated by Spivak, 1976). However, this paper also looks to texts within contexts in order to explore the historical context of a text. The purpose is to perform an act of reflexivity (Lawson 1985) which seeks to critically explore assumptions regarding cohesion in knowledge domains. The criticality of reflexivity adopted in this paper stems from a postmodern view which seeks to explore the ambiguity, uncertainty, discontinuity and diversity often denied in rational analyses of history. In this paper the view taken of history in relation to the disciplinary body of knowledge called information systems is closer to a genealogical view (Foucault 1979; Preston 1991) than to a view of history as singular in rationality, linear in temporality and discoverable in a factual manner.

The primary purpose of this paper is to demonstrate the importance of historical contexts in the writing of an interpretive information systems ethnography. The broad historical context is that of the information systems discipline during the adaptation of an approach from another discipline. In adaptation, one discipline decontextualizes an approach from the debates of its source discipline and then recontextualizes it within its own ongoing disciplinary body of knowledge. A secondary purpose is to return to the debates in the source discipline's historical contexts in order to contribute to the debates on ethnography in the adapted context of information systems research.

After the initial introduction to the debates on ethnography in the source discipline of anthropology, an information systems ethnography is selected and reread in order to illustrate the issues arising from the source debates. The chosen text is taken as a representation of a novice text, being an unpublished Ph.D. thesis, and is chosen to provide initial illustrations of the struggles of using ethnography. It has been selected because:

- it illustrates the adoption of ethnography to information systems research at a particular point in the history of that research,

- it uses an already adapted approach to ethnography, organizational ethnography, which is then adapted again to the information systems area, recognizing that this may have provided a means for genre exploration not otherwise available,

- it was completed by an information systems researcher rather than by a researcher from a source discipline in ethnography, and

- although originally a novice text, it is now recognized as an important qualitative information systems research thesis as shown by subsequent writings which have originated from the thesis and have had important impact in the interpretive information systems research community (Orlikowski 1991a, 1992b; Walsham 1995).

This acceptance of a Ph.D. work as a central contribution to the field of information systems research indicates the relative lack of more advanced works from senior peers in the discipline prior to Orlikowski's ethnography. Although some anthropologists and historians had written ethnographic theses on information systems topics, there is a noticeable lack of Ph.D. theses from the information systems discipline at that 
time. The most commonly cited information systems ethnography is Zuboff (1988), which is a doctoral ethnographic work conducted as an organizational researcher rather than as an information systems researcher. The Ph.D. thesis by Orlikowski is seemingly the first notable doctoral ethnography produced in the United States by an information systems researcher. This indicates the potential historical significance of the chosen text.

The Orlikowski Ph.D. text is deconstructed through an analysis of genres which are argued to show shifts in the acceptability of schools of thought, most noticeably the shifts from a realist perspective to an impressionist one. The socio-historical contexts of the writing of the thesis are then introduced in order to interpret something of the shifts. The purpose of this is to show how genres vary in knowledge transition and is not to criticise the text for inconsistency. On the contrary, the text is shown to be a good example of a postmodern decalage of genres, indicating shifts which are likely to lead to further genre inconsistency as new debates arise during the process of knowledge change in the information systems research community. The genre inconsistency is a sign of non-determinism in a postmodern knowledge era. This is consistent with the values of postmodernism. The conclusion of the paper discusses the importance of reflecting upon socio-historical contexts when both writing and reading an ethnographic text as a contribution to information systems research.

\section{A BRIEF SUMMARY OF ETHNOGRAPHIC DEBATES}

Due to the obvious spatial limitations of this paper, the debates from the source discipline of anthropology have to be presented extremely briefly and are summarized due to the assumption that many of the readers will not have had first hand knowledge of them.

The main philosophical dimensions of ethnography have centered around the intention of the ethnographer to represent a culture. The assumptions often expressed are that cultures have hidden logics which can be uncovered by an intelligent observer who immerses herself/himself into the membership of that culture. The ethnographer seeks to decipher the code which makes up the logic of that culture, always standing by the assumption that there is a single, dominant logic to any culture. The codes to be deciphered are in the form of rituals, language, dress, community and family structures and political and economic practices. The ethnographer as informed observer then writes an ethnography which represents the culture as a logical system of rationalities, values, beliefs and actions. The purpose of conducting an ethnography is to uncover this logical system as the ethnographer attempts to minimize the intervention effects of searching for this system (Evans-Pritchard 1940; Geertz 1963; Sahlins 1972; Leach 1976; Cohen 1982).

Geertz (1973) challenges the assumptions of ethnography as a means of uncovering culture. He argues that the act of conducting an ethnography is essentially an interpretive act. This acceptance of interpretivism at the point of observation has chal- 
lenged ethnographic practices which concentrate on gathering examples of cultural behavior while interposing a theoretical model of a system of logic, attributing this model to the situation and not to the theorist observing the situation (Atkinson 1992). Marcus and Fischer (1986) take the debate further, while still adopting a genre of scientific discourse, discussing the changing nature of anthropological research. Within sociology and philosophy, the rise of postmodernism has also challenged assumptions regarding the treatment of culture as a rational object (Lyotard 1984; Kroker and Cook 1988). Diversity of interpretation has emerged at this time as an alternative to representation (Clifford and Marcus 1986).

The representation school of thought views culture as something that can be captured, decoded and represented as a theoretical model, leading to the writing of ethnographic texts as if they represent a reality. This is described by Van Maanen (1988) as a realist tale. Although somewhat simplistic in its analysis and presentation, the Van Maanen text provides a useful initial introduction to ethnographic debates by categorizing ethnographies into three distinct types which he names as three tales. These are the realist tale, the confessional tale and the impressionist tale. From a broad interpretation, the realist tale describes ethnographies which seek to represent a culture. The realist ethnographic texts are non-reflexive and so lack a critical dimension in relation to the author's construction of the text. The confessional tale appears to be a transitional form of writing, away from realism and toward postmodernism, as expressed through the intensive acceptance of the need for authorial subjectivity. The impressionist tale seeks to evoke impressions of the events in the reader, to consider the creative act of developing a text as a discourse between reader and writer. Comparing the three categories, the primary differences between approaches to ethnography can be summarized as points along a continuum. At one end is ethnographer as scientist, seeking to uncover, decode and represent a culture. At the other is ethnographer as artist, seeking to explore the experiences of belonging to a culture and seeking to develop a text which invites the reader to relive those experiences through evoking images in the discourse between the writer and the reader. The writer expresses the experience to try to evoke that experience in the reader and this is how the ethnographer's experience of a culture is transferred into a text. Considering the ethnographer as scientist, the important discovery is the system of logic. In the case of the ethnographer as artist, the important act is the reflexive writing of a text. With one the challenge is to discover while with the other the challenge is to write evocatively. This distinction is further explored below.

\subsection{The Ethnographer's Interests}

Observation versus creation is central to the differences between the genres as is the authorizing of the text. Observation which does not declare the interests of the writer is authorizing a text to be a discourse of authority. Conversely, a text which declares the interest of the writer and brings that to the fore as critical to the attempt to evoke experiences is authorizing the text as an open debate, inviting the reader to contribute 
to the process of experience evocation. The ethnographic text differs dramatically depending upon which of the opposing ends of the spectrum is adopted. Most ethnographic texts are likely to fall between the two ends and many will be a mixture of genres along the continuum.

An ethnography is fundamentally a writing (graphy) of a culture (ethno). It is always a text that illustrates the researcher's interests and cannot simply be a recording of a stream of events in a situation. The ethnographer selects from the situation those aspects of interest to her/him. This selection process is important as it shapes how the ethnographer will interact with those in the field and then, subsequently, how the ethnographer will choose to write the ethnographic text. This simple point has been central in debates on ethnography. Early ethnographic texts give the reader the impression that the fieldworker simply observed what happened in cultures in a neutral manner and then recorded the observations in order to represent the culture in detailed models. The ethnographer's intent is placed in the background which gives the author an unchallenged authority when writing the ethnographic text and claiming that it is a representation of a culture (Clammer 1984; see also Van Maanen's discussion on realist tales [Van Maanen 1988, pp. 45-72] and Geertz's discussions of Malinowksi's posthumous confessions [Geertz 1983, pp. 55-59]). During the last two decades, there have been critical debates in anthropology which deny that authority and demand that ethnographers challenge their own assumptions regarding their intentions and write their ethnographic texts in a critical and reflexive voice (see the debates in Clifford and Marcus 1986). The writing of an ethnographic text is currently viewed in anthropology as an inescapably political act where the ethnographer is seen as purposefully selecting from the setting a story to be told. Texts are written with the voice of recognition that the telling of that story can also change either the situation or others' attitudes toward that situation.

\subsection{Genres}

In writing an ethnography, the author is no longer considered the authoritative controller of the interpretation of the text. The relationship between author, reader and text has been at the center of debates on ethnography. It is now recognized that there are many different genres in ethnographic writings (Marcus 1980; Clifford and Marcus 1986; Geertz 1988; Van Maanen 1988; Hammersley 1990; Atkinson 1992). These genres represent a continuing shift over the last two decades accentuated by the debates on what is acceptable as an ethnographic genre.

At the risk of further over-simplification, an illustration of extremes in the genre debate is now presented, moving from the seemingly acceptable genre found earlier in the debates into what is now arguably viewed as the desired genre. The contrast gives an impression of clarity in change. This is illusory as the change has not necessarily been smooth, nor has it been universal. The dangers of using a "categorize and contrast" approach to the presentation of history are obvious and the reader needs to remain aware of the simplification this creates. The reader also needs to 
recognize that, in constructing this text, the author has purposefully chosen this particular view of history.

\section{Genre 1: Ethnographer as Scientist}

An ethnographic text can simply be presented as a description. Its primary purpose may be to represent something to do with culture. A good descriptive writing would challenge the writer to represent as close to the actual event or situation as possible. This form of writing (representation) is evaluated on its depth and accuracy of representation. Theory is introduced by framing the representation as a system of logic and the disciplinary reasoning appears to be to find universals of logic systems from the analyses of comparative cultures. The reader's potential for interpretation is minimized as the writer seeks to control the ambiguity of the representative text.

To show the rigor in the representation, the writer is expected to confer with those involved in the event or with responsibility for the situation being represented. This form of ethnography assumes that authoritative knowledge lies with informants in situations and that the ethnographer's task is to represent the culture in which the informant exists.

The key issues for the ethnographer are in collecting adequate data from accurate sources and in using triangulation to develop a representation that truly represents what is being written about so that those who are not able to have access to that culture can understand it from the ethnographer's text.

In information systems research, this form of ethnography may represent events such as the implementation of a new system and the resultant change. There would be a key informant, probably in the form of a senior IT manager, and the ethnographer would have delivered an interpretation of the event back to a group of people in the situation in order to confirm that the representation is an accurate portrayal of events. The ethnographer is unlikely to challenge the authoritative capabilities of either those in the context or herself/himself as author.

This form of ethnography can be described under the realist tale as categorized by Van Maanen. The genre of a realist tale reads with the authority of a scientific script in that the author treats her/his textual representation as an objective account with the language being third party ("the analyst designed a system") rather than first party ("I saw the analyst's work and interpreted it as a design for a system"). Realist tales also adopt a documentary style as if the author is reporting on the micro-level aspects of an event in such a way as to discover something not obvious but hidden.

The author of a realist ethnography presents herself/himself as essentially outside the situation, observing, recording and analyzing rather than actively involved in the creation of the representation of that situation. In this way, the realist approach mimics the laboratory context of the scientist who observes and records in order to analyze and represent in the form of a model that can be generalized to other contexts.

The ethnographer mines the situation for minute details that wait for her/his intervention and do not change form when discovered. Meaning is merely hidden in symbols and the ethnographer seeks to discover it and decode the symbols. 
The realist position is seemingly acceptable, and commonly found within information systems ethnographies. The problems of adopting a realist stance become more obvious when the debates from the source disciplines are addressed. Geertz (1988) presents a detailed argument against a realist stance, calling for a recognition of the ethnographer's active part in authorizing a text as opposed to viewing the ethnographer as the recorder of a culture. This argument is developed and supported by later ethnographers who adopt a critical or postmodern perspective (Clifford and Marcus 1986; Tyler 1986; Kroker and Cook 1988; Clough 1992; Myers 1994; Harvey and Myers 1995). By adopting a realist voice, information systems researchers will be obliged to actively deny the arguments made against this voice by the ethnographers cited above. As we are addressing the argument from a historical and contextual perspective, no claim can be made in an absolute manner against a realist stance. Instead, the claim is being made that information systems researchers who choose a realist position are choosing to reject the debates from the most recent historical ethnographers within the context of anthropological research. This acceptance indicates that information systems ethnographers choose to view their ethnographic contributions to the discipline as beyond the critiques of the anthropological ethnographers. If it is the case that the realist voice remains dominant within information systems research, then it follows that information systems ethnography is choosing to separate itself from anthropological ethnography at this point in history. The contexts become purposefully distinct and the adaptation becomes limited.

In order to show the distinctions more clearly, a polarized perspective to the realist tale is presented below.

\section{Genre 2: Ethnographer at Play}

At the other extreme to the realist perspective, an ethnography can be a means for evoking the imagination. The primary purpose here is not to represent but to involve the reader in an evocative experience which the writer puts forward. The writer then invites the reader to join with her/him in the experience of the interpretation.

With this approach, no two interpretations are ever expected to be the same as all readers are going to be different. Also, this approach fundamentally values history, the history of the context and the history of the writing/reading experience. Every new reading of the text is a new interpretation. The ethnographic text is never static and so does not seek to be an ultimate representation. Instead, the text is intended to be a tale that evokes ideas and images and which brings forward experiences. This is similar to what Van Maanen refers to as an impressionist tale.

Writers of this type of ethnography would see themselves as a critical part of the tale and would seek to write the text in that attitude. The language is likely to be subjective with first person referencing, talking of experiences and seeking to find imaginative ways of evoking the experiences in the mind of the reader. This may be by using analogies, allegories, poetry, or even music to seek to invoke an experience in the reader (Newman 1989). The writer is aiming to share the interpretive experience which is unfolding while critically challenging personal views on the situation. 
The "text" can take many forms and is often intentionally obtuse (Baudrillard 1988). The aim is to leave purposeful space for ambiguity to develop so that readers can construct their own interpretations from the images put forward. This form of ethnography sees "art as experience" as being the guiding model for the writing of the ethnographic text. The text is more likely to read like a novel than like an objective report.

The purpose of this form of ethnography is to embellish the material so that experiences can emerge. Simply representing a culture is not treated as worthwhile in and of itself. The ethnographer has a responsibility to expand upon the text of the situation in order to invite the reader into a discourse with the text. When this experience is entered into, the reader can step out of the obvious, consider the absurd and then return to the obvious with fresh eyes. The process allows for novelty rather than just for representation.

This perspective is often referred to as postmodern ethnography. Tyler describes postmodern ethnography as "a fantasy reality of a reality fantasy whose aim is to evoke in reader and writer alike some intimation of a possible world already given to us in fantasy and commonsense" (Tyler 1986, p. 134).

The postmodern ethnography reads as a novel, is often disjointed, building upon many experiences which are juxtaposed. The concern of the author is more with aesthetics than with objective representation as she/he invites the reader-writer discourse in a historically-dependent contextual world. The evocation of the history and contexts through juxtaposition of experiences is the important criterion for judging the success of the ethnography. The success is not in representing a reality but in evoking a discursive experience. It is more concerned with creative play than with scientific discovery. It also accepts the essentially political nature of that play and does not neutralize the notion of knowledge by claiming that it can be apolitical. Hence, a postmodern ethnography is often concerned with the political nature of discourse both within situations and within texts which discuss situations, i.e., ethnographic writings. Lyotard (1984) provides a clear and thorough treatise on postmodernism. Lyotard's (1989) short summary of debates in postmodernism is also helpful in clarifying the problems with interpreting this genre.

In summary, the first extreme presented here seeks to represent in an objective format by drilling down into data. It appears to be highly analytical. The second extreme seeks to evoke an imaginative discourse by moving out from the text of the situation in order to explore alternatives before returning to the text, treating this as a discourse between text, writer and reader. The discourse is, at each reading, a further reconstruction of the text. It appears to be highly creative. The first extreme adopts a scientific reporting genre and the second extreme adopts an "artist at play" genre. The artist's genre tends to be heavily involved in debates concerned with the politicizing of texts, calling upon postmodernist social theory to enhance those debates (see the preface in Kroker and Cook 1988). 


\section{REVISITING AN INFORMATION SYSTEMS ETHNOGRAPHIC TEXT}

In this section, Orlikowski's Ph.D. thesis is deconstructed (Orlikowski 1988). The thesis, being an unpublished text, demonstrates the struggles of writing a doctoral work thatis the source by which the author is examined as a competent new researcher. In retextualizing Orlikowski's text, the purpose is to discourse with the reader concerning Orlikowski's contribution within the information systems research context of 1988.

At the start of the thesis, the term genre is used to present the research area which is "the role of information technology in organizational processes" (p. 1). Taking that a genre is a style, often of literature, this simple introductory statement implies that the chosen research area adopts a textual form which is retextualized in the thesis. The use of the term genre indicates immediately that the thesis is presenting a different perspective than found at that time in information systems research.

The initial language of the thesis also breaks with tradition at that time in that the author uses first person when describing how the thesis will unfold. There is also discussion at many points throughout the thesis regarding what motivates the research, a highly subjective account when compared to the depersonalized accounts of information systems research in the journals at that time. Orlikowski uses the terms "we" and "ours" which invites the reader into a shared community, hence illustrating a postmodern voice and further denying the scientific genre of objectivity. Discussions are made of a "point of view" and a "standpoint" to show that the author is aware of the potential different readers of the thesis (p. 3).

After introducing the reader early in the thesis text to a subjective style, the latter part of this first chapter then reverts back to the more scientific reporting style. From section 1.3 to the end of the first chapter (page 6 through page 14), there is only one subjective reference to "I." More generally, the reference switches from the author as subject to the study as object using terms such as "this research," and "this research study." "The central concern of this research" is discussed instead of "I am concerned in carrying out this research with." Future research is discussed in relation to "findings established by this study" as if the study has a life independent of the author. Similarly, the description of the thesis is presented as chapters which conduct acts, e.g." "The chapter also presents a critique," thus depersonalizing the script and giving authority to the text rather than declaring that the author chooses to present a critique. Finally, this chapter discusses how "the research concludes" and the reader has lost the sense of direct interaction with the author.

A comparison between the objective reporting text and an alternative, subjective discourse, approach is shown below to illustrate the point.

Actual text (page 13): "This research study is premised on the notion that so little is known" 
Alternative: "In carrying out this research, I was working on the notion that so little is known"

Actual text (page 13): "Future research will build on the framework and findings established in this study."

Alternative: "It may be that those who choose to enter this discourse in the future find some use for the interpretations and the frameworks which I have put forward in this ethnographic text."

Actual text (page 14): "The research then concludes with a discussion of the study's limitations"

Alternative: "As an arbitrary closure to our discourse, we can challenge the text to question the limitations of our interpretations"

The stylistic changes in this introductory chapter move from the subjective invitation from the author to the reader to take part in a discourse on the research puzzle, onto the objective presentation of the text as an authoritative and factual report on the knowledge argument. Even when the ethnographic fieldwork is discussed, this tension between two genres does not shift. The genre mix of adopting the stance of scientific reporting while using first person on occasion is retained throughout the thesis, at least until section 12.4 onward (final chapter, pages 439-446).

Up to the final sections, the text of the thesis reads as a realist tale, even though the first person is used on many occasions. This genre dominates despite the opening invitations and the use of first person. From page 439 onward, the genre moves away from a representative mode, through subjectivity and towards attempting to evoke impressions and experiences in the reader. The language changes occur when Orlikowski starts to reflect upon future research. The reader is given the impression that the author's controlled, objective reporting task is complete and so self-reflection and imagination can now be more freely expressed.

A small part of the final section of Orlikowski's ethnographic text is now deconstructed in order to show how a rereading of the text evokes an experience of the tensions between the various genres in her written text.

Orlikowski writes (all emphases are added by the author of this paper) "this study represents [realist choice of word] but the first forays into a phenomenon [the romantic style of the artist] that I believe [subjective disclosure of the confessional]." The thesis then continues with "I intend [subjective disclosure of the confessional] pursuing [artist's genre: romantic metaphor of 'the chase'] further indepth studies similar to this one to try and obtain some verification [scientific reporting of the realist] and elaboration [the artist's genre of extension] of the findings [scientific genre - mining for the truth] that emerge [the artist's genre of interpretation] from this study [depersonalisation language of the scientific reporting of realism] (page 439).

Orlikowski's thesis provides an evocative confusion for the interpretive reader. Despite the use of first person throughout the text, the thesis is presented as authoritative reporting. The thesis is a rational representation which then disturbs the reader by blending in the genre of subjectivity. The final section is the most evocative as the styles mingle and change. The reader is presented with a realist report of a situation 
which then switches and changes as the genre of artist emerges through an exploration of the implications of the text.

In order to situate the thesis as a text within a historical context, the deconstruction now extends beyond the text to seek to interpret how the contexts relevant to the writing of the thesis may have shaped and limited the genre switching.

\subsection{History, Context and Text}

Orlikowski's thesis was originally written in a particular time and shaped by related contexts. The contexts are discussed and then the deconstruction of the text is revisited to try and interpret why the thesis appears to work in different genres while being dominated by the realist's genre.

Context 1: Orlikowski's thesis is a Ph.D. thesis and, therefore, a traditional document in that it is written for an ancient purpose. That purpose has the full weight of many centuries of historical norms behind it, making it a highly authoritative norm. $\mathrm{A} \mathrm{Ph} . \mathrm{D}$. is seen as a rite of passage where those who are nominated as gatekeepers for knowledge pass a judgment on the text (the thesis). That judgment will have widereaching repercussions on the future of the writer. The wider context of the writing of the thesis is the political context of academia.

Context 2: Orlikowski submitted the thesis as a candidate of the Leonard N. Stern School of Business, New York University. This prestigious business school is situated in a long established university with an international reputation for quality. The disciplinary implication is that a traditional university, and prestigious business school, would be likely to indicate to doctoral candidates a preference for traditional research during candidacy. Radical research would have to prove itself in a quality debate against traditional measures in order to ensure that high standards are maintained. Doctoral candidates, being disempowered novices, are least likely to be accepted for adopting radical research genres during a candidacy.

Context 3: The information systems research community in the United States did not appear to have a high acceptance of radical research methods in the late 1980s (Orlikowski and Baroudi 1991). Publications show that more radical approaches were accepted in European and Scandinavian writings rather than in American journals. A Ph.D. candidate is expected to publish from their research and so the choice to move outside of the traditional publication arena of the student's country would be a difficult one for a candidate to sustain. The publishing and career context in the United States is likely to caution the candidate against adoption of a radical voice.

Context 4: The chosen subject area of information systems and organizations does allow for a move into the area of organizational research. It is here that the study of organizational culture dominated in the late $1980 \mathrm{~s}$ and that more radical critiques of the area were emerging (postmodernism was discussed in relation to gender and work, power relationships at work, etc.). Working in this context would allow the author 
of the thesis more freedom to explore the radical than in an information systems research context at that time.

The first three of these contexts are likely to have constrained Orlikowski's act of writing the Ph.D. text. This would be particularly true when any attempt is made to sustain a confessional or impressionist genre. The author was politically predisposed to occupy a realist stance while writing as a doctoral candidate in the historical context of the university, the country and the information systems research community. The fourth context allowed Orlikowski some room for exploration. It may even be that this context encouraged a more radical ethnographic voice in order to fit the thesis into the acceptable debate within anthropology and organizational research. The thesis represents a "radical" writing in a highly traditional knowledge domain and the montage of genres in the text evokes an image of the tension between the radical and the traditional.

\section{CONCLUSION}

The issue that arises for qualitative information systems research in using ethnography as an approach is whether the traditional is still dominating to an extreme. If it is, then the debates in anthropology in relation to ethnography which have occurred over the last two decades are unlikely to be allowed space in the discourse of information systems research. This means that any ethnographers who are also an information systems researchers are likely to live in a world of tensions when working on their texts. It also means that the ethnography-based information systems research produced is likely to be rejected by the source disciplines as naive, if not highly contentious.

Since 1988, there have been many instances of qualitative research which adopt ethnographic techniques being accepted into the information systems research domain. A highly selective few are referenced in this paper's introduction. The contexts in which Orlikowski's thesis was being developed are also likely to have experienced some form of historical shift. If these assumptions are reasonable, ethnography in information systems research will be open to the continuing adaptation of the debates from the source disciplines. If this is not the case, then information systems ethnographies are becoming disassociated from the source disciplines, indicating that information systems is a traditional discipline with a preference for a scientific genre as opposed to a postmodern genre. This would make the historical context difficult for those ethnographers within information systems research who would choose to adopt a postmodern stance, declaring the intention of the ethnographer in a more selfreflective and critical manner and attempting to deconstruct the political nature of ethnographic texts.

A critical or postmodernist stance challenges assumptions when looking at sensemaking in organizations. Questions are asked such as 
- What is the writer assuming an information system is seen to be in the context being visited?

- What are the selected assumptions regarding intervention in the issues in which the ethnographer may be involved?

- Does the ethnographer ignore the criticisms from individuals who tell them they are incorrect in their interpretations, instead choosing to argue for the discovery of a system of logic, claiming that this is essentially hidden from those within the situation?

- Are the representative ethnographers denying the images that they experience because they are in conflict with what is taken to be a logical system?

- Does the creative act of looking for alternative images seem too artistic, i.e., too far removed from scientific research?

- Does the ethnographer consider that a representation should be constructed rather than actively creating a discursive text as a discourse with those in the situation and future readers?

All these questions are challenges for information systems ethnographers who may find themselves in genre confusion. The extent of the persistence of that confusion is likely to depend upon the historical shifts of information systems research as a disciplinary domain of knowledge.

In this paper, a text has been deconstructed in order to show flux in historical genre changes. The main purpose has been to demonstrate the importance of history and context in the writing of an ethnographic text. Reading a text as a representation of knowledge, disembodied from history and context, is a highly restrictive form of inquiry. It limits the inquiry to a confined appreciation of the rationality of theoretical principles. These can only be fully appreciated when placed in historical contexts, that is, when appreciated as an essentially political act of writing. Critically reflecting on the historical contexts of a text allows for a fuller appreciation of both the concepts of that text and their wider relationship as expressed forms in an emerging and changing body of knowledge known as a discipline. Information systems ethnographies can be more fully appreciated for their contribution to the information systems discipline when interpreted both in history and in context. This includes a consideration of the histories and contexts of both writing an ethnography and of the subsequent readings of an ethnographic text.

It is hoped that we have succeeded in this paper in both our primary purpose of demonstrating the importance of historical contexts in ethnographic writing and in our secondary purpose of furthering the debates on ethnography in the adapted context of information systems research.

\section{POSTSCRIPT}

This postscript is written as a commentary on the historical and contextual shaping of this text to date. In writing this postscript, the intention is not to criticize the 
reviewers of the paper but to critically reflect on the discourse which has already occurred between the author, the reviewers as readers and the deconstructed/reconstructed text of this version of the paper.

The original draft of this paper was a mixture of the subjective and the objective voices. The reviews indicated a range of problems with the genre and voice of that script. It will be noticeable to the alert reader that the genre of this version of the paper is observational, seeking to avoid the obvious dominance of a postmodern voice, particularly as this is the preferred voice of the author. This has occurred through following all the indicated requirements of the reviewers. All references to authors' first names have been removed (as explicitly requested) as have all personalizations of the script. It is only in this postscript commentary that a critical self-reflection of this text as a discourse within a historical context has been attempted.

One review expressed strong value judgments against the critical postmodern genre discussed here. Value-laden statements were made which evoked a clear distaste for the postmodern stance, even though the reviewer is obviously well-versed in ethnography. The second review showed a concern with the difficulty of writing in a consistent genre while critically being reflective, recognizing how challenging selfreflective writing is and also providing useful and helpful comments. The third review was immediately accepting of the script while also fundamentally challenging assumptions in the text and providing helpful comments. Together, the three reviews demonstrated various degrees of unease in accepting a text which does not comply with an assumed tradition in interpretive information systems research. With respect to the reviewers, and in recognition of the socio-historical context in which I am currently writing, I have changed the obvious genre of the paper while retaining much of the challenge and debate. This indicates further concerns for ethnographers in information systems research who are keeping abreast with the debates in the source discipline while attempting to contribute to the information systems research discipline.

It is also recognized by myself, as author, that the original version of this paper was far less sophisticated than this version and that the change is due to the contributions from the reviewers. What has been removed, in all areas apart from this section, is the highly subjective and purposefully creative style of this author, an exploratory style which is preferred by the author as a postmodern writer and ethnographer.

A deconstruction of the original text, the reviews and the reconstructed text is likely to give a further indication of the 1996 historical context of interpretive information systems research in relation to debates on ethnography as is the placing of this text against other texts in the conference. This author suspects that a decalage of genres and tales will be present in the conference, indicating the fertile nature of the debates in this disciplinary area. 


\section{REFERENCES}

Atkinson, P. (1992). Understanding Ethnographic Texts. Newbury Park, California: Sage Publications Qualitative Research Methods Series 25.

Avison, D. E., and Myers, M. D. (1995). "Information Systems and Anthropology: An Anthropological Perspective on IT and Organizational Culture." Information Technology and People, Volume 8, Number 3, pp. 43-56.

Baudrillard, J. (1988). America. London: Verso.

Clammer, J. (1984). “Approaches to Ethnographic Research.” In R. F. Ellen (Editor), Ethnographic Research: A Guide to General Conduct. Londo: Academic Press, pp. 63-85.

Clifford, J., and Marcus, G. E. (Editors) (1986). Writing Culture: The Poetics and Politics of Ethnography. Berkeley: University of California Press.

Clough, P. T. (1992). The Ends of Ethnography. Newbury Park, California: Sage. Cohen, A. P. (Editor) (1982). Belonging: Identity and Social Organisation in British Rural Cultures. Manchester, England: Manchester University Press.

Davies, L. (1993). "A Workshop on Two Techniques for Qualitative Analysis: Interviewing and Evaluation." In J. . DeGross, R. P. Bostrom, and D. Robey (Editors), Proceedings of the Fourteenth International Conference on Information Systems, December 5-8, Orlando, Florida, p. 399.

Davies, L. J., and Nielsen, S. (1992). "An Ethnographic Study of Configuration Management and Documentation Practices in an Information Technology Center." In K. E. Kendall, K. Lyytinen, and J. I. DeGross (Editors), The Impact of Computer Supported Technology on Information Systems Development. Amsterdam: North Holland Press, pp. 179-192.

Derrida, J. (1976). Of Grammatology, translated by G. Spivak. Baltimore: John Hopkins University Press.

Evans-Pritchard, E. (1940). The Nuer: A Description of the Modes of Livelihood and Political Institutions of a Nilotic People.

Foucault, M. (1979). The History of Sexuality, Volume One: An Introduction. Middlesex, England: Penguin.

Geertz, C. (1963). Peddlers and Princes. Chicago: University of Chicago Press.

Geertz, C. (1973). The Interpretation of Cultures. New York: Basic Books.

Geertz, C. (1983). Local Knowledge: Further Essays in Interpretive Anthropology. New York: Basic Books.

Geertz, C. (1988). Works and Lives: The Anthropologist as Author. Cambridge, England: Polity Press.

Hammersley, M. (1990). Reading Ethnographic Research: A Critical Guide. London: Longman.

Harvey, L. J., and Myers, M. D. (1995). "Scholarship and Practice: The Contribution of Ethnographic Research Methods to Bridging the Gap." Information Technology and People, Volume 8, Number 3, pp. 13-27. 
Kroker, A., and Cook, D. (1988). The Postmodern Scene: Excremental Culture and Hyper-Aesthetics. Basingstoke, England: Macmillan Education.

Lawson, H. (1985). Reflexivity: The Post-Modern Predicament. London: Hutchinson.

Leach, E. (1976). Culture and Communication. Cambridge, England: Cambridge University Press.

Lee, A. (1992). "A Workshop on Two Techniques for Qualitative Data Analysis: Action Research and Ethnography." In J. I. DeGross, J. D. Becker, and J. J. Elam (Editors), Proceedings of the Thirteenth International Conference on Information Systems, December 13-16, 1992, Dallas, Texas, pp. 305-306.

Lee, A. (1993). "Electronic Mail as a Medium for Rich Communication: An Empirical Investigation Using Hermeneutic Interpretation.” In J. I .DeGross, R. P. Bostrom, and D. Robey (Editors), Proceedings of the Fourteenth International Conference on Information Systems, December 5-8, 1993, Orlando, Florida, pp. 13-22.

Lyotard, J.-F. (1984). The Postmodern Condition: A Report on Knowledge. Manchester, England: Manchester University Press.

Lyotard, J.-F. (1989). "Defining the Postmodern." In L. Appignanesi (Editor), Postmodernism: ICA Documents. London: Free Association Books.

Marcus, G. (1980). "Rhetoric and the Ethnographic Genre in Anthropological Research." Current Antrhopology, Volume 21, pp. 507-510.

Marcus, G. E., and Fischer, M. J. (1986). Anthropology as Cultural Critique: An Experimental Moment in the Human Sciences. Chicago: The University of Chicago Press.

Myers, M. (1994). “A Disaster for Everyone to See: an Interpretive Analysis of a Failed IS Project." Accounting, Management and Information Technology, Volume 4, pp. 185-201.

Newman, M. (1989). “Revising Modernism, Representing Postmodernism.” In L. Appignanesi (Editor), Postmodernism: ICA Documents. London: Free Association Books.

Orlikowski, W. J. (1988). "Information Technology in Post-Industrial Organizations: An Exploration of the Computer-Mediation of Production Work." Unpublished Ph.D. thesis, Leonard N. Stern School of Business, New York University, New York.

Orlikowski, W. J. (1991a). "Integrated Information Environment or Matrix of Control? The Contradictory Implications of Information Technology." Accounting, Management and Information Technologies, Volume 1, Number 1, pp. 9-42.

Orlikowski, W. J. (1991b). "A Workshop on Two Techniques for Qualitative Data Analysis: Analytic Induction and Hermeneutics." In J. I. DeGross, I. Benbasat, G. DeSanctis, and C. M. Beath (Editors), Proceedings of the Twelfth International Conference on Information Systems, December 16-18, 1991, New York. 
Orlikowski, W. J. (1992a). "Learning from Notes: Organizational Issues in Groupware Implementation." Proceedings of the Conference on Computer-Supported Cooperative Work (CSCW'92). New York: ACM Press.

Orlikowski, W. J. (1992b). "The Duality of Technology: Rethinking the Concept of Technology in Organizations." Organization Science, Volume 3, Number 3, pp. 398-427.

Orlikowski, W. J., and Baroudi, J. J. (1991). "Studying Information Technology in Organizations: Research Approaches and Assumptions." Information Systems Research, Volume 2, Number 1, pp. 1-28.

Preston, A. M. (1991). "The 'Problem' in and of Management Information Systems." Accounting, Management \& Information Technologies, Volume 1, Number 1, pp. 43-70.

Sahlins, M. (1972). Stone Age Economics. London: Tavistock.

Tyler, S. A. (1986). "Post-Modern Ethnography: From Document of the Occult to Occult Document." In J. Clifford and G. E. Marcus (Editors), Writing Culture: The Poetics and Politics of Ethnography. Berkeley: University of California Press.

Van Maanen, J. (1988). Tales of the Field: On Writing Ethnography. Chicago: The University of Chicago Press.

Walsham, G. (1995). "The Emergence of Interpretivism in IS Research." Information Systems Research, Volume 6, Number 4, pp. 376- 394.

Zuboff, S. (1988). In the Age of the Smart Machine. New York: Basic Books.

\section{BIOGRAPHY}

Lynda Harvey is professor of Information Systems and Head of the School of Information Systems at Curtin University of Technology in Perth, Australia. She specializes in the application of ethnographic research methods to the investigation of information systems in organizations. She has worked as a management consultant advising on change management issues as well as having been in academia in England and Australia for over twelve years. Lynda is associate editor of Information Technology and People. She has coauthored a book and numerous research papers on information systems management in organizations. She has been an active member of IFIP 8.2 for ten years. 